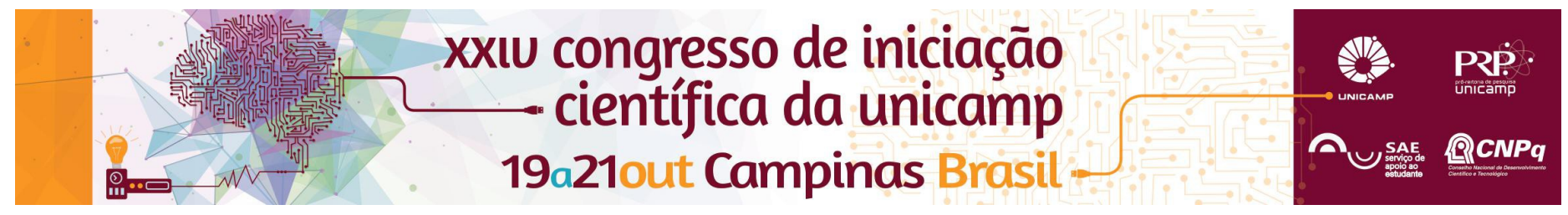

\title{
Trabalho Final de Graduação - Uma análise do ensino e aprendizagem em Arquitetura e Urbanismo
}

\author{
Dínamis Luã de França Lara*, Ana Maria Reis de Goes Monteiro
}

\begin{abstract}
Resumo
Esta pesquisa de caráter documental teve como propósito a formulação de um banco de dados dos Trabalhos Finais de Graduação do curso de Arquitetura e Urbanismo da Universidade Estadual de Campinas. Para tanto, buscou-se nos arquivos da Faculdade de Engenharia Civil, Arquitetura e Urbanismo - FEC as informações referentes aos trabalhos dos anos de 2004 até 2014, levantando, dentre outros tópicos, os autores, orientadores, temas, local de projeto e a avaliação na banca examinadora. Os projetos arquitetônicos levantados - em sua maioria, propostas para a região central de Campinas - justificam o caráter público da universidade, ao se tratar de propostas aos problemas urbanos como moradia, mobilidade e acesso à informação, de modo que o retorno à sociedade seja feito da melhor maneira possível. O material levantado será disponibilizado ao curso AU/Unicamp, para estudos futuros e para acesso da comunidade universitária.
\end{abstract}

\section{Palavras-chave:}

Trabalho Final de Graduação, Ensino e Aprendizagem em Arquitetura, Ensino e Aprendizagem de Projeto.

\section{Introdução}

Os trabalhos finais no término dos cursos de arquitetura tiveram o caráter de interdisciplinaridade e síntese, desde a proposta do Trabalho de Graduação Interdisciplinar - TGI (idealizado e implantado em 1971 por Hélio de Queiroz Duarte), até a implantação do TFG (Trabalho Final de Graduação), atualmente utilizado pelos cursos de Arquitetura de todo país pela Portaria/MEC 1.770/94.

Ao analisar os TFG é possível identificar algumas linhas de pensamento presentes em cada época, em relação ao ensino e aos conceitos a serem explorados em Arquitetura. O Grande Prêmio de Roma, por exemplo, consagrava ideais clássicos do estilo greco-romano; o Exame de Diplomação, por sua vez, mostrava-se mais moderno no uso de novas tecnologias e materiais disponíveis, contrapondo-se ao ensino das escolas Belas Artes; os Trabalhos de $5^{\circ}$ ano possuíam tendências clássicas nas Escolas Politécnicas, ideais muitas vezes contrapostos posteriormente com a criação da FAU/USP. O TFG tem como finalidade não só identificar aspectos sobre a transição do meio acadêmico para o profissional, mas a cima de tudo, identificar escolas e modelos de ensino de Arquitetura e Urbanismo; saberes, motivações e crenças individuais, sociais e institucionais, a fim de evidenciar os ideais presentes no cursos, e se eles são adequados à proposta do TFG.

\section{Resultados e Discussão}

Destaca-se aqui o papel de instituições como a Associação Brasileira de Ensino de Arquitetura e Urbanismo, na realização de seminários e encontros para melhorias no ensino e aprendizagem nesta área e a Comissão do TFG, formada por docentes do curso AU/Unicamp para coordenar a produção dos trabalhos. Os trabalhos foram levantados segundo o Projeto Pedagógico do curso AU/Unicamp e seguem as exigências nele contido; abordagens como o direito à cidade e moradia, mobilidade urbana e ensino e aprendizagem foram recorrentes nestes TFGs.
Conclui-se que os trabalhos em seus temas, representam a proposta do Projeto Pedagógico do Curso AU/Unicamp, na formação de Arquitetos e Urbanistas empenhados em discutir soluções para os problemas urbanos, da vontade de grupos sociais, não só individuais; possíveis conclusões serão atingidas em um segundo momento desta pesquisa, com análise mais detalhada dos projetos em si.

\section{Agradecimentos}

Agradecimentos ao PIBIC, pelo incentivo à pesquisa e pela divulgação dos trabalhos através dos congressos; em especial ao SAE/UNICAMP, que viabilizou esta pesquisa através da bolsa de Iniciação Científica e a minha orientadora, Ana Maria Reis de Goes Monteiro, pelo apoio e pelo incentivo às pesquisas em ensino e aprendizagem em Arquitetura e Urbanismo.

ARCIPRESTE, Cláudia Maria. Entre o discurso e o fazer arquitetônico: reflexões sobre o ensino de arquitetura e urbanismo e seus referenciais a partir do trabalho final de graduação. Tese (Doutoramento em Arquitetura). Faculdade de Arquitetura e Urbanismo da Universidade de São Paulo. São Paulo, 2012.

GUTIERREZ, Ester Judite Bendjouya; MARAGNO, Gogliardo Vieira; MONTEIRO, Ana Maria Reis de Goes; SANTOS JUNIOR, Wilson Ribeiro dos. A Construção de um novo olhar sobre o ensino de Arquitetura e Urbanismo no Brasil: os 40 anos da associação brasileira de ensino de arquitetura e urbanismo Dissertação. ABEA. Brasília, 2013.

MACEDO, Daniel Fernandes. Sobre projetos, palavras e imagens: relacionando textos e desenhos nos trabalhos finais de graduação em arquitetura e urbanismo. Dissertação (Mestrado em Arquitetura e Urbanismo). Universidade Federal do Rio Grande do Norte. Natal, 2010.

MALACRIDA, Sérgio Augusto. Trabalho de Graduação Interdisciplinar (TGI): origens e problematização da proposta implantada em 1971 na Faculdade de Arquitetura e Urbanismo da Universidade de São Paulo (FAU/USP). Dissertação (Mestrado em Educação). Universidade Federal de São Carlos. São Carlos, 2004.

MARQUES, Ricardo Barros. A Relação professor-aluno e a afirmação do discente como sujeito do processo projetual: um estudo exploratório sobre a produção do Trabalho Final de Graduação em Arquitetura e Urbanismo na UFC e na UFRN. Dissertação (Mestrado em Arquitetura e Urbanismo). Universidade Federal do Rio Grande do Norte. Natal, 2010.

Projeto Pedagógico

Diretoria Acadêmica - Regimento Geral de Graduação. In: http://www.dac.unicamp.br/portal/grad/regimento/regimento_completo/ Acesso em 13/05/2016 